\title{
Phase-equilibrium-dominated vapor-liquid-solid mechanism: further evidence
}

\author{
Yongliang Zhang, Jing Cai, Qiang Wu*, Xizhang Wang, Lijun Yang, Chengyu He and Zheng Hu*
}

\begin{abstract}
Prediction and design of various nanomaterials is a long-term dream in nanoscience and nanotechnology, which depends on the deep understanding on the growth mechanism. Herein, we report the successful prediction on the growth of $\mathrm{AlN}$ nanowires by nitriding $\mathrm{Al}_{69} \mathrm{Ni}_{31}$ alloy particles across the liquid-solid $(\beta)$ phase region $\left(1133-1638^{\circ} \mathrm{C}\right)$ based on the phase-equilibrium-dominated vapor-liquid-solid (PED-VLS) mechanism proposed in our previous study. All predictions about the growth of AIN nanowires, the evolutions of lattice parameters and geometries of the coexisting Al-Ni alloy phases are experimentally confirmed quantitatively. The preconditions for the applicability of the PED-VLS mechanism are also clarified. This progress provides the further evidence for the validity of the PED-VLS mechanism and demonstrates a practical guidance for designing and synthesizing different nanomaterials according to corresponding phase diagrams based on the insight into the growth mechanism.
\end{abstract}

Keywords nanowires growth; prediction; growth mechanism; phase equilibrium; quantitative experimental analysis

\section{INTRODUCTION}

Nanomaterial synthesis is experiencing a profound evolution from the empirical science ("cook-and-look") to prediction and design which depends on the deep insight into the growth mechanism [1-3]. A typical empirical synthesis is the growth of various one-dimensional (1D) nanomaterials by the classical vapor-liquid-solid (VLS) process, which was first proposed in 1964 [4] and is the most popular method today [5-8]. Due to its great success and significance, persistent effort has been devoted to exploring the origin of the VLS process over the past half-century. Especially, by applying the advanced in situ microscopic technique, the real-time nucleation and growth process of individual nanowires has been directly observed and the involved kinetics is studied thoroughly [9-16]. Despite such kind of progresses, the precise prediction on nanomaterial synthesis is still a great challenge. Based on the quantitative experimental analysis, recently we proposed the phase-equilibrium-dominated VLS (PED-VLS) mechanism for the growth of h-AlN nanowires by nitriding $\mathrm{Al}_{69} \mathrm{Ni}_{31}$ particles in the liquid-solid $(\delta)$ phase region $\left(854-1133^{\circ} \mathrm{C}\right)$ [17]. Specifically, at a certain temperature, the yield of AlN nanowires and the composition of the residual Al-Ni alloy are determined by the Al-Ni binary phase diagram. This specific example reveals the possibility to predict and design nanomaterials according to the corresponding phase diagrams. Herein we report the successful prediction of the growth of AlN nanowires by nitriding $\mathrm{Al}_{69} \mathrm{Ni}_{31}$ alloy particles across another liquid-solid $(\beta)$ phase region $\left(1133-1638^{\circ} \mathrm{C}\right)$. By using the rapid quenching and growth tracing approaches, all expectations about the growth of the AlN nanowires, the evolutions of lattice parameters and geometries of the coexisting Al-Ni alloy phases were experimentally confirmed quantitatively. The preconditions for the applicability of the PED-VLS mechanism were also clarified. This study provides the further evidence for the PED-VLS growth mechanism, and also corroborates its validity in designing $1 \mathrm{D}$ nanostructures.

\section{EXPERIMENTAL SECTION}

\section{Nitriding $\mathrm{Al}_{69} \mathrm{Ni}_{31}$ alloy particles and quenching the products}

Nitridation of $\mathrm{Al}_{69} \mathrm{Ni}_{31}$ alloy particles is similar to that in our previous study [17] but in different temperature range, i.e., in the region II of Fig. 1a. The $\mathrm{Al}_{69} \mathrm{Ni}_{31}$ particles were dispersed on an alumina plate, and then mounted at the center of a tube furnace (Supplementary information, Fig. S1). The $\mathrm{Al}_{69} \mathrm{Ni}_{31}$ alloy particles consist of two phases of o- $\mathrm{Al}_{3} \mathrm{Ni}$ and $\mathrm{h}-\mathrm{Al}_{3} \mathrm{Ni}_{2}$ (Fig. S2) with size distribution in the range of $1 \sim 100 \mu \mathrm{m}$ [17]. After being pumped and flushed by Ar for several times to remove oxygen and moisture, the furnace was heated up to a desired temperature under $\mathrm{N}_{2}$ flow of $100 \mathrm{~mL} \mathrm{~min}{ }^{-1}$. After $2 \mathrm{~h}$ nitridation, the product was pushed into liquid $\mathrm{N}_{2}$ cooling zone for rapid quenching to avoid phase separation. For comparison, the products were also obtained by slow cooling, i.e., naturally-cooling

Key Laboratory of Mesoscopic Chemistry of MOE, School of Chemistry and Chemical Engineering, Nanjing University, Nanjing 210023, China "Corresponding authors (emails: wqchem@nju.edu.cn (Wu Q); zhenghu@nju.edu.cn (Hu Z)) 
to ambient temperature in the furnace, and in this case the phase separation might occur.

\section{Tracing the growth of AlN nanowires out of a specific particle}

$\mathrm{Al}_{69} \mathrm{Ni}_{31}$ particles were scattered on an alumina wafer. The growth of AlN nanowires out of an identified Al-Ni particle was traced by scanning electron microscopy (SEM). Specifically, the identified Al-Ni particle was first nitrided slightly below the phase transition temperature of $1133^{\circ} \mathrm{C}$ and SEM image was recorded. Then, the same particle was further nitrided slightly above $1133^{\circ} \mathrm{C}$ and SEM image was obtained again. Thus the morphological evolution was traced.

\section{Monitoring the heat flow and weight change during nitridation}

Nitridation process was monitored in situ by thermogravimetry-differential scanning calorimetry (TG-DSC, STA449F3 thermal analyzer, Netzsch) from room temperature to $1400^{\circ} \mathrm{C}$ at a heating rate of $10^{\circ} \mathrm{C} \mathrm{min}^{-1}$ in $\mathrm{N}_{2}$. The control experiment was performed by keeping additional $1 \mathrm{~h}$ at $1050^{\circ} \mathrm{C}$ during nitridation. The survey in Ar was also conducted for comparison.

\section{Sample characterizations}

The products were characterized by SEM (Hitachi S-4800), high resolution transmission electron microscopy (HRTEM, JEM-2100) attached with an energy dispersive X-ray spectroscopy (EDS) detector, and also precisely identified by X-ray diffraction (XRD, Bruker D8 Advance X-ray diffractometer, $\mathrm{Cu} \mathrm{Ka}$, scan speed: 0.15 s per step, step size: 0.019757 ).

\section{RESULTS AND DISCUSSION}

In preparing $\mathrm{AlN}$ nanowires, the source $\mathrm{Al}_{69} \mathrm{Ni}_{31}$ particles consist of two phases of $\mathrm{o}-\mathrm{Al}_{3} \mathrm{Ni}$ and $\mathrm{h}-\mathrm{Al}_{3} \mathrm{Ni}_{2}$ (Supplementary information, SI 1). As well known, in the liquid-solid ( $\delta$ ) two-phase region $\mathrm{I}\left(854-1133^{\circ} \mathrm{C}\right)$ (Fig. 1a), the $\mathrm{Al}_{69} \mathrm{Ni}_{31}$ particles experience a PED-VLS growth to form h-AlN nanowires and coexisting solid solution of $\delta$ phase (denoted by h- $\mathrm{Al}_{3} \mathrm{Ni}_{2}$ ). The composition of the $\delta$ phase changes along the solidus $c d$ with increasing the nitridation temperature. And the measured weight gain due to the formation of h-AlN nanowires is in quantitative agreement with the theoretical calculation according to the PED-VLS mechanism [17].

Based on the PED-VLS mechanism, we predict the growth of AlN nanowires in the liquid-solid ( $\beta$ ) two-phase
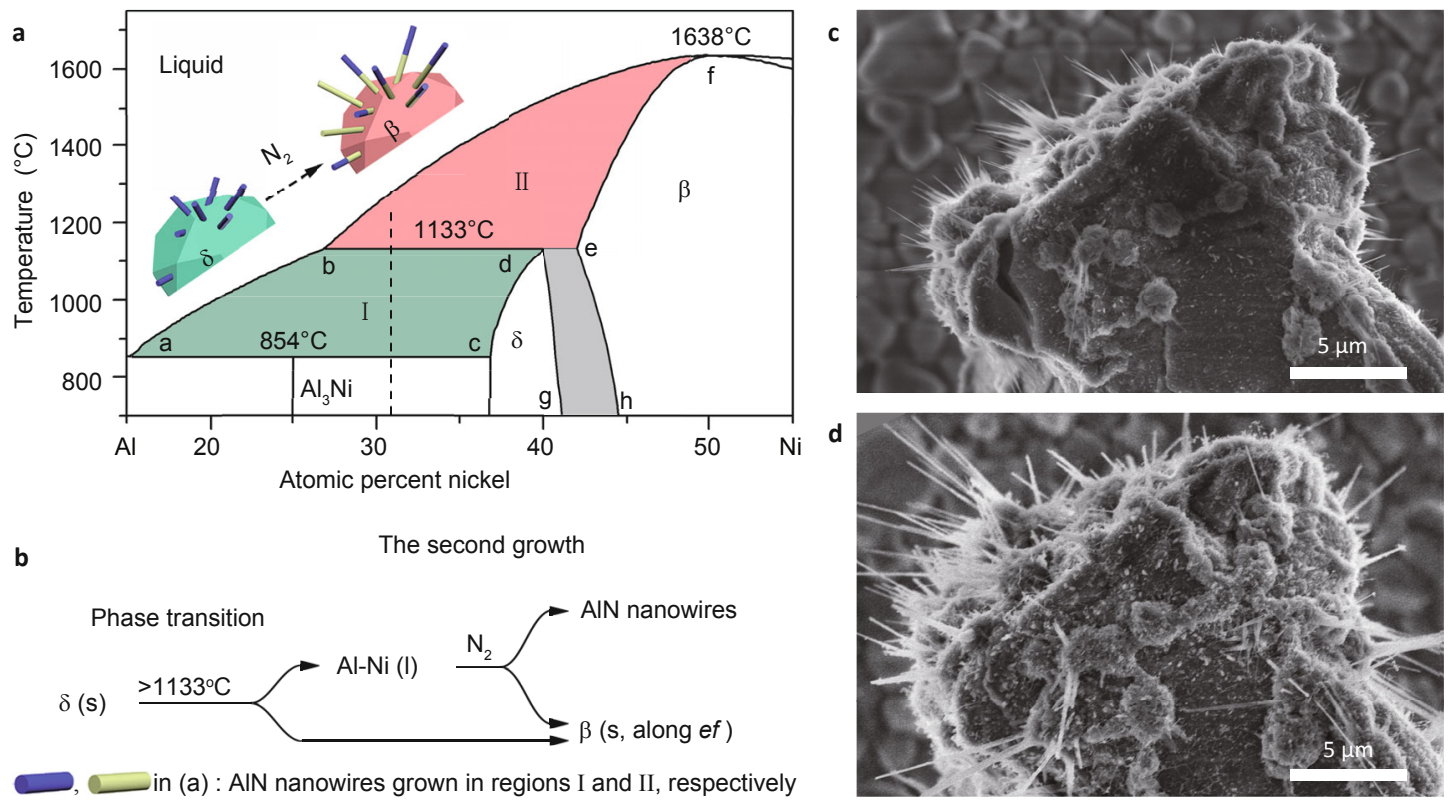

Figure 1 Predicting and tracing the second-stage growth of h-AlN nanowires. (a) Al-Ni phase diagram (data from [18]). The dashed line highlights the composition of the $\mathrm{Al}_{69} \mathrm{Ni}_{31}$ alloy. (b) Prediction on the second-stage growth of $\mathrm{h}$-AlN nanowires by increasing the nitridation temperature across the phase transition from region I into II in (a) at $1133^{\circ} \mathrm{C}$ based on the PED-VLS mechanism. The schematic second-stage growth is also shown in the inset in (a). (c and d) SEM images of an identified $\mathrm{Al}_{69} \mathrm{Ni}_{31}$ alloy particle after nitridation at $1100^{\circ} \mathrm{C}$ for $2 \mathrm{~h}$ (c), followed by additional $2 \mathrm{~h}$ nitridation at $1200^{\circ} \mathrm{C}(\mathrm{d})$. 
region II $\left(1133-1638^{\circ} \mathrm{C}\right)$, as schematically shown in Figs 1a and $\beta$. First, with further increasing the nitridation temperature across $1133^{\circ} \mathrm{C}$ from region I into region II, the new liquid Al-Ni phase and solid $\beta$ phase (c-AlNi) will appear at the expense of the $\delta$ solid $\left(\mathrm{h}-\mathrm{Al}_{3} \mathrm{Ni}_{2}\right)$ due to its incongruent melting. This means that some additional $\mathrm{Al}$ species will be 'unfrozen' during this transition and interact with nitrogen to form AlN. Accordingly, a second-stage growth of AlN nanowires will occur following the firststage growth in phase region I, accompanied by forming additional $\beta$ phase while keeping the geometry approximately unchanged. Second, the composition of the $\beta$ phase should change along the solidus ef (Fig. 1a) with increasing the nitridation temperature. Third, the amount of AlN nanowires formed at a specific temperature, which can be experimentally measured, should also be in quantitative agreement with that predicted by the PED-VLS mechanism. These three predictions are indeed experimentally confirmed as following.

First, the second-stage growth of AlN nanowires is evidenced by tracing the growth on an identified $\mathrm{Al}_{69} \mathrm{Ni}_{31}$ alloy particle as shown in Figs $1 \mathrm{c}$ and $d$. The particle was completely nitrided at $1100^{\circ} \mathrm{C}$ in region I for $2 \mathrm{~h}$, and SEM reveals many AlN nanowires growing out of the particle (Fig. 1c). Then, the same particle was nitrided at $1200^{\circ} \mathrm{C}$ in region II for additional 2 h (Fig. 1d). By comparing Figs $1 \mathrm{c}$ and $\mathrm{d}$, we find that the nanowires in Fig. 1c become longer in Fig. 1d and some new nanowires appear, while the coexisting Al-Ni bulk almost maintaines its geometry (Fig. S3). The growth of AlN nanowires out of the coexisting AlNi bulk was confirmed by SEM, TEM and EDS characterizations on the products obtained at different nitridation temperatures (Fig. 2). Generally more AlN nanowires grow out of the Al-Ni alloy particles at higher nitridation temperature (Fig. 2a). The traced second-stage growth of AlN nanowires results from the emerging $\mathrm{Al}-\mathrm{Ni}$ liquid phase due to the phase transition, i.e., the incongruent melting of the $\delta$ solid, by increasing the nitridation temperature across $1133^{\circ} \mathrm{C}$, as expected from the PED-VLS mechanism (Figs $1 \mathrm{a}$ and $\mathrm{b}$ ). The second-stage growth of AlN nanowires and their increasing tendency with nitridation temperature are also confirmed by in situ TG-DSC examination discussed later. Notably, the growth of AlN nanowires here follows the VLS mechanism, different from the dislocation-driven growth of AlN nanohelixes [19] and nanowires [20].

Second, the evolution of the products with different nitridation temperature in region II is characterized by XRD. The high-resolution spectra and derived results are presented in Fig. 3. The product is composed of h-AlN and c-AlNi ( $\beta$ ) (Fig. S4), which is different from that consisting of h-AlN and h- $\mathrm{Al}_{3} \mathrm{Ni}_{2}(\delta)$ formed in the first-stage growth in region I [17]. The disappearance of $h-\mathrm{Al}_{3} \mathrm{Ni}_{2}(\delta)$ and the appearance of c-AlNi $(\beta)$ are in agreement with the anticipation of the PED-VLS mechanism (Figs 1a and b). We observed that the rapid-quenching technique is required to keep the state after the nitridation, otherwise phase separation of the solid c-AlNi $(\beta)$ might occur during the slow cooling, leading to the appearance of $\mathrm{h}-\mathrm{Al}_{3} \mathrm{Ni}_{2}$ (SI 3). Generally, the relative intensity of the diffraction peaks for h-AlN shows an increasing tendency with elevating the nitridation temperature as expected (Fig. S4), in accordance with the intuitive SEM observation on the evolution of the nitridation products (Fig. 2a). Furthermore, from the local enlargement of the XRD patterns, it is clearly seen that the three characteristic peaks of (100), (002), and (101) for h-AlN have negligible shift (Fig. 3a). In contrast, the three characteristic peaks of (100), (110), and (211) for c-AlNi show progressive shifting toward the lower angles as increasing reaction temperature, with better resolution at the higher angle side in the order of group $(100)<(110)<$ (211) (Figs $3 \mathrm{~b}$ and SI 4), arising from the increasing lattice parameter $a$ (Fig. 3c). The temperature dependence of the lattice parameter $a$ is re-plotted as the corresponding composition dependence by referring to the phase diagrams $[18,21]$, and presented as the red and blue curves in Fig. $3 \mathrm{~d}$. Surprisingly, the changing behavior is in quantitative agreement with that for $\mathrm{Al}-\mathrm{Ni}$ alloy along solidus ef $(\mathrm{Ni}$ content: $42-50$ at.\%) [22,23], with a systematic error of $\mathrm{Ni}$ content of ca. 2 at.\% (or lattice parameter of ca. $0.007 \AA$ ) in reference to the updated data of 1972 [23] (Figs 3d and SI 5 ). This result proves that the composition of the $\beta$ phase in the product indeed changes along the solidus ef with increasing the nitridation temperature.

Third, the nitridation process of the $\mathrm{Al}_{69} \mathrm{Ni}_{31}$ particles has been in situ examined by TG-DSC in a wide temperature range up to $1400^{\circ} \mathrm{C}$, as depicted in Fig. 4. Briefly, the two endothermic peaks at ca. 859 and $1133^{\circ} \mathrm{C}$ in the DSC curves (either in Ar or in $\mathrm{N}_{2}$ flow) come from the respective phase transitions (Fig. 1a), and the additional broad exothermic peak in $\mathrm{N}_{2}$ centered at $938.4^{\circ} \mathrm{C}$ comes from the nitridation of the Al-Ni particles. The TG curve in inert Ar is featureless, while that in $\mathrm{N}_{2}$ presents an increasing tendency following the first phase transition due to the growth of AlN nanowires. It is worth noting that an upward step appears in the TG curve following the second phase transition (Fig. 4a), also reflected by the peak starting at $1134.2^{\circ} \mathrm{C}$ in the corresponding differential TG (DTG) curve (Fig. S6a). This phenomenon is in agreement with the observed second-stage growth of AlN nanowires on the identified $\mathrm{Al}_{69} \mathrm{Ni}_{31}$ alloy particle (Figs 1c and d). Such 
a

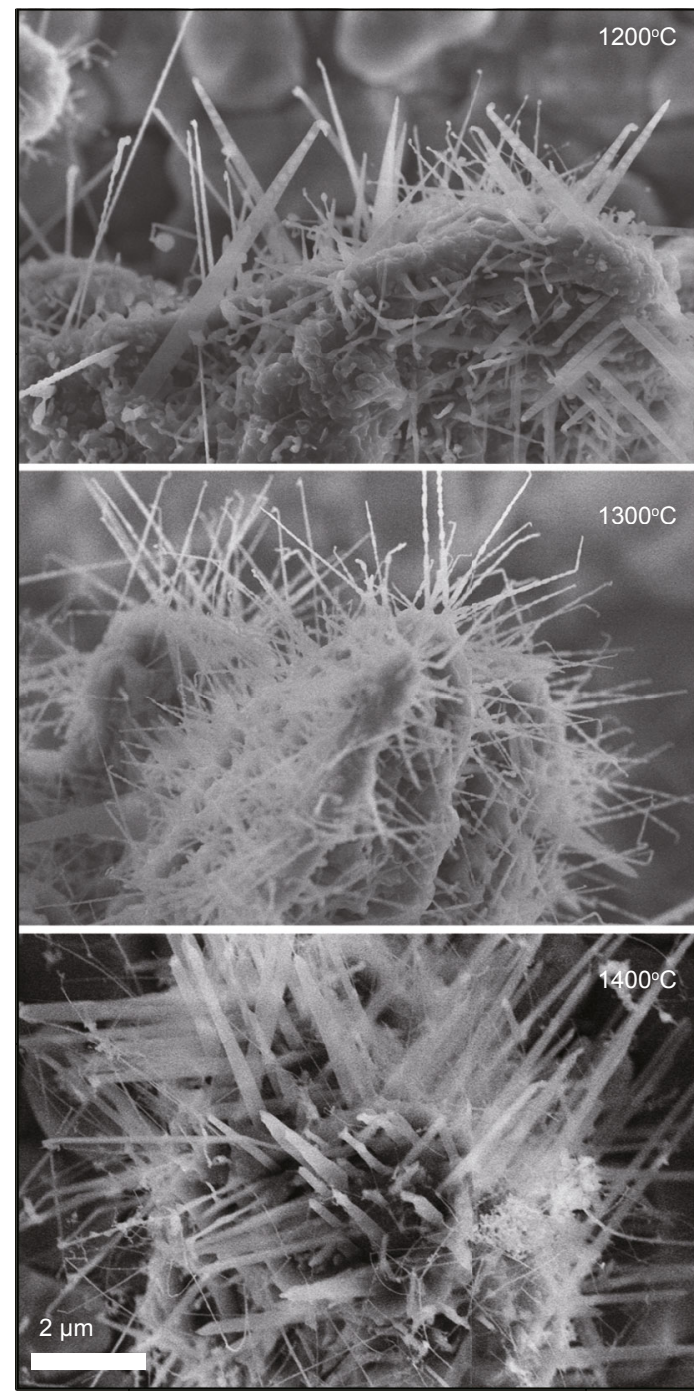

b

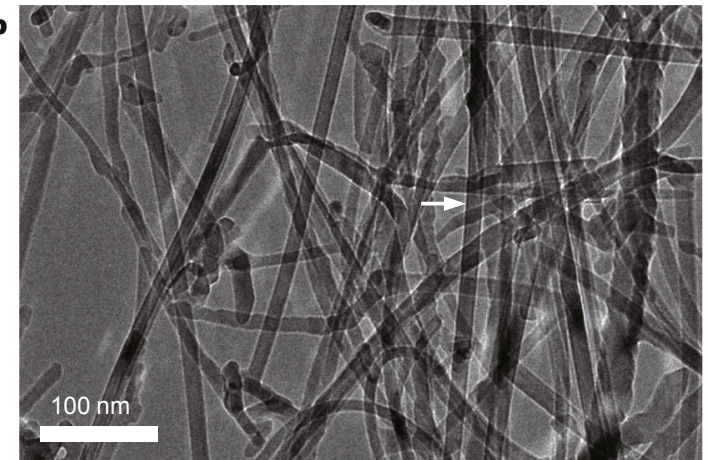

c

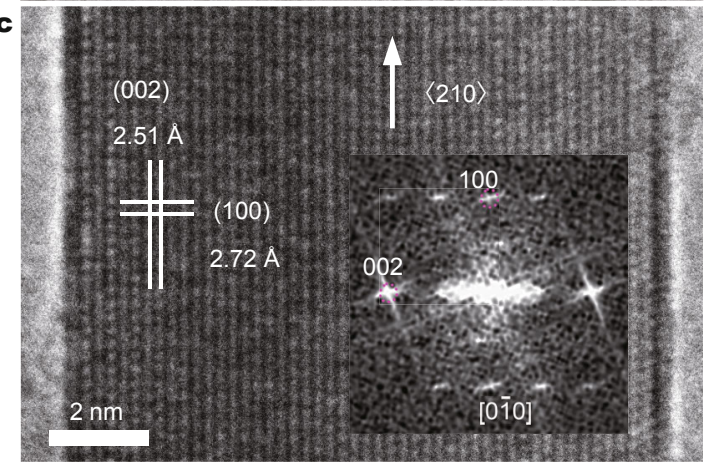

d

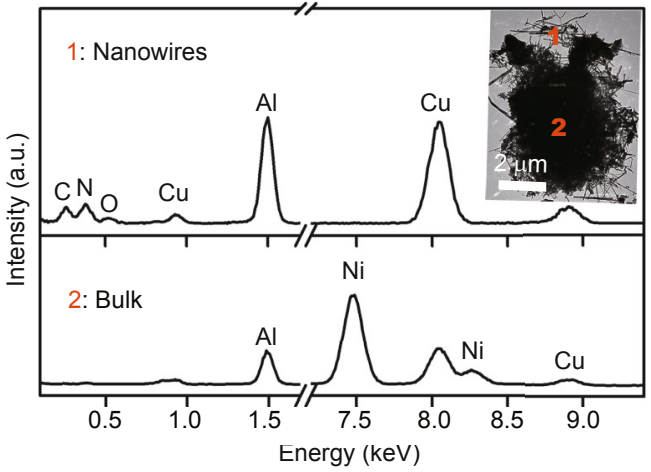

Figure 2 SEM, TEM and EDS characterizations. (a) Typical SEM images of the products obtained at 1200,1300 and $1400^{\circ} \mathrm{C}$. (b) TEM image of the AlN nanowires. (c) HRTEM image of a typical nanowire in (b) marked by the white arrow. Inset is the corresponding fast Fourier transform (FFT) pattern. The interplanar spacings of 2.72 and $2.51 \AA$ correspond to the $d_{(100)}$ and $d_{(002)}$ values for h-AlN. (d) EDS spectra taken from the nanowires (site 1 ) and bulk (site 2). The nanowires consist of $\mathrm{Al}$ and $\mathrm{N}$ elements, and the coexisting bulk consists of $\mathrm{Al}$ and Ni elements. $\mathrm{C}$ and Cu signals come from the TEM grid.

phenomenon is even more obvious by keeping additional $1 \mathrm{~h}$ at $1050^{\circ} \mathrm{C}$ for full nitridation and then further raising it across the second phase transition (SI 7). Thanks to the sufficient nitridation time, in this case the liquid Al-Ni phase formed below $1050^{\circ} \mathrm{C}$ is completely consumed for forming AlN nanowires. With the less interference of the hysteretic nitridation reaction, the weight gain from the second-stage growth following the second phase transition is more prominent, and the corresponding DTG signal also becomes much stronger (Fig. S7a).

Moreover, the weight gain read from the TG curve quantitatively coincides with the theoretical calculation based on the PED-VLS mechanism in the whole temperature range (Figs $4 \mathrm{c}$ and SI 8). Specifically, the experimental and theoretical weight gains exhibit a quite similar increasing tendency $v s$. temperature even in the detail of the upward step for the second-stage growth of AlN nanowires following the phase transition at $1133^{\circ} \mathrm{C}$. Generally, the experimental value is a bit smaller than the theoretical value, and the deviation between them is getting smaller with increasing the nitridation temperature and approaching zero at $1400^{\circ} \mathrm{C}$. Such deviation comes from the hysteretic nitridation of the liquid Al-Ni phase due to the kinetic limitation in the continuous temperature-rising manner, 

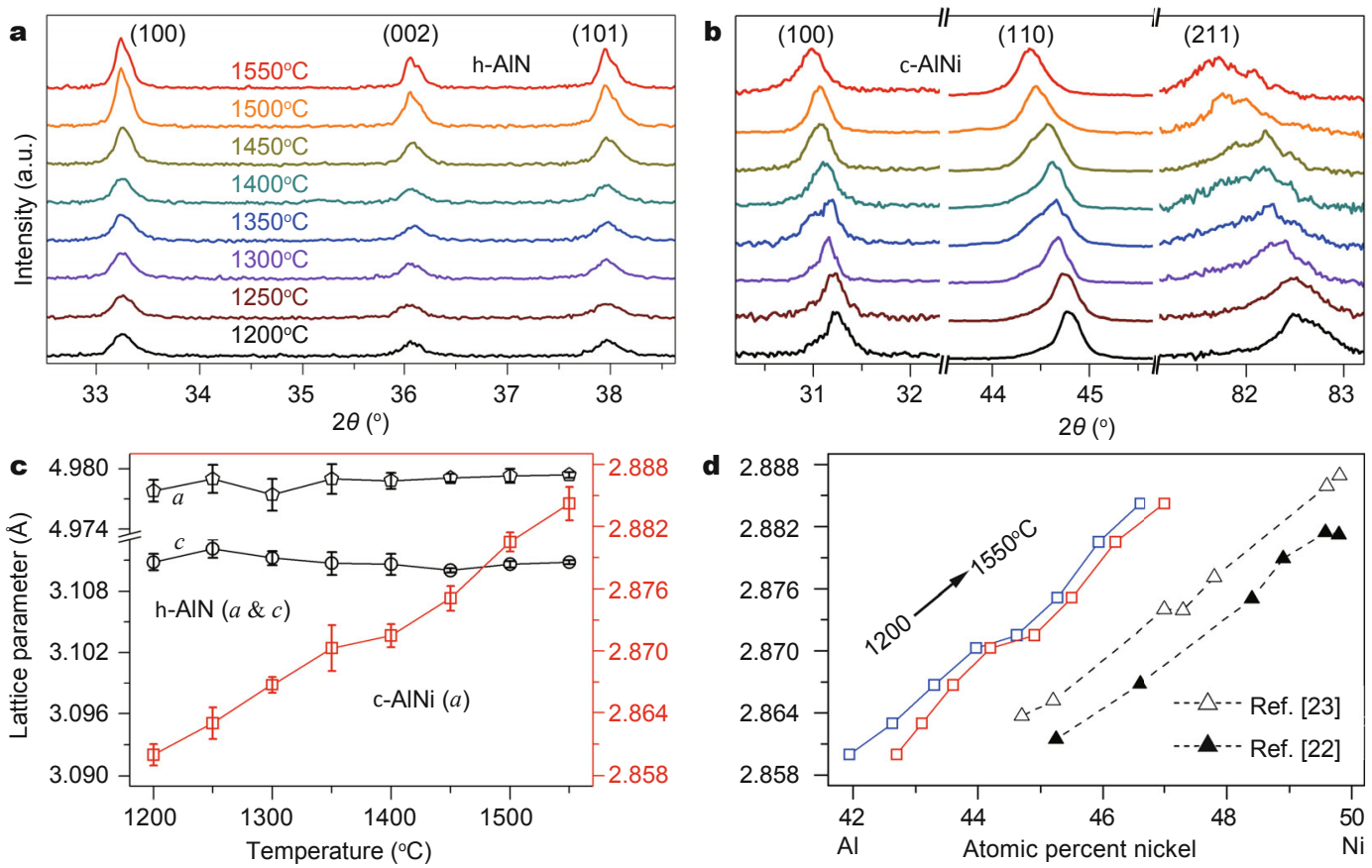

Figure 3 Quantitative XRD characterization of the nitridation products. (a) The (100), (002), and (101) peaks of h-AlN with negligible peak shift for the products with different nitridation temperatures. (b) The (100), (110), and (211) peaks of c-AlNi ( $\beta$ ) showing the progressive down-shifting with increasing the nitridation temperature. (c) Lattice parameters $a$ and $c$ of the h-AlN (black) and lattice parameter $a$ of the c-AlNi (red) $v s$. growth temperature (SI 4). (d) Composition dependence of the lattice parameter $a$ of the c-AlNi. The data are converted from the corresponding temperature dependence

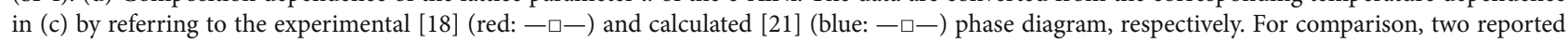
relationships of the lattice parameter $v$ s. composition of $\beta$ phase (c-AlNi) along solidus ef are also listed in (d) (black: $-\mathbf{\Delta}-;-\triangle-$. Data from [22,23]).

especially at low temperature side for the low reaction rate. This argument is confirmed in our control experiment by fully nitriding the alloy at $1050^{\circ} \mathrm{C}$ for additional $1 \mathrm{~h}$, which leads to a continuous increase of the weight gain from the initial $6.2 \%$ to $7.7 \%$ of ca. 40 min later, and then keeping unchanged in the following 20 min (Expt. ${ }^{\text {b }}$ * in Figs $4 \mathrm{c}$ and S7a). The weight gain of $7.7 \%$ at $1050^{\circ} \mathrm{C}$ is indeed very close to the theoretical values (Theor.: $-\mathbf{-}-$ and Theor. ${ }^{\mathrm{d}}$ : - - in Fig. 4c) predicted by the PED-VLS mechanism. The less obvious upward step in the experimental curve than those in the two theoretical curves also results from the hysteretic nitridation. Therefore, the experimentally measured weight gain due to the growth of AlN nanowires is in quantitative agreement with the prediction of the PED-VLS mechanism.

The preceding experimental results clearly indicate that all the predictions on the second-stage growth of AlN nanowires by nitriding $\mathrm{Al}_{69} \mathrm{Ni}_{31}$ particles in the liquid-solid $(\beta)$ phase region of $1133-1638^{\circ} \mathrm{C}$ (Figs $1 \mathrm{a}$ and $\mathrm{b}$ ) are proved not only qualitatively but also quantitatively. The successful predictions provide the further evidence for the validity of the PED-VLS growth mechanism in designing $1 \mathrm{D}$ nanostructures.
However, it should be pointed out that in some cases the PED-VLS mechanism is not applicable. For instance, in the efforts to prepare $\mathrm{ZnO}$ nanowires by oxidizing $\mathrm{Cu}_{66} \mathrm{Zn}_{34}$ alloy [24] and $\mathrm{In}_{2} \mathrm{~S}_{3}$ nanowires by sulfurizing $\mathrm{Cu}_{11} \mathrm{In}_{9}$ alloy [25], the predictions of the PED-VLS mechanism are ineffective. For the former, the growth happened as the $\mathrm{Cu}_{66} \mathrm{Zn}_{34}$ alloy still existed in the solid single-phase region, i.e., before entering the liquid-solid two-phase region. For the latter, though the $\mathrm{Cu}_{11} \mathrm{In}_{9}$ alloy was in the liquid-solid two-phase region, both phases reacted with the introduced gaseous $\mathrm{H}_{2} \mathrm{~S}$, thus $\mathrm{CuInS}_{2}$ film rather than $1 \mathrm{D} \mathrm{In}_{2} \mathrm{~S}_{3}$ nanowires was formed. In principle, for binary alloys, the PED-VLS mechanism works only when the liquid phase in the liquid-solid two-phase region (e.g., the liquid Al-Ni in regions I or II in Fig. 1a) can selectively react with the introduced gaseous reactant (e.g., $\mathrm{N}_{2}$ in this study). In other words, the appearance of the liquid-solid two-phase coexistence and the selective reaction of the introduced gaseous reactant with the liquid phase are two preconditions when applying the PED-VLS mechanism for the prediction and design of $1 \mathrm{D}$ nanomaterials.

Attention should also be paid to optimizing the experimental condition, e.g., by prolonging reaction time, to min- 

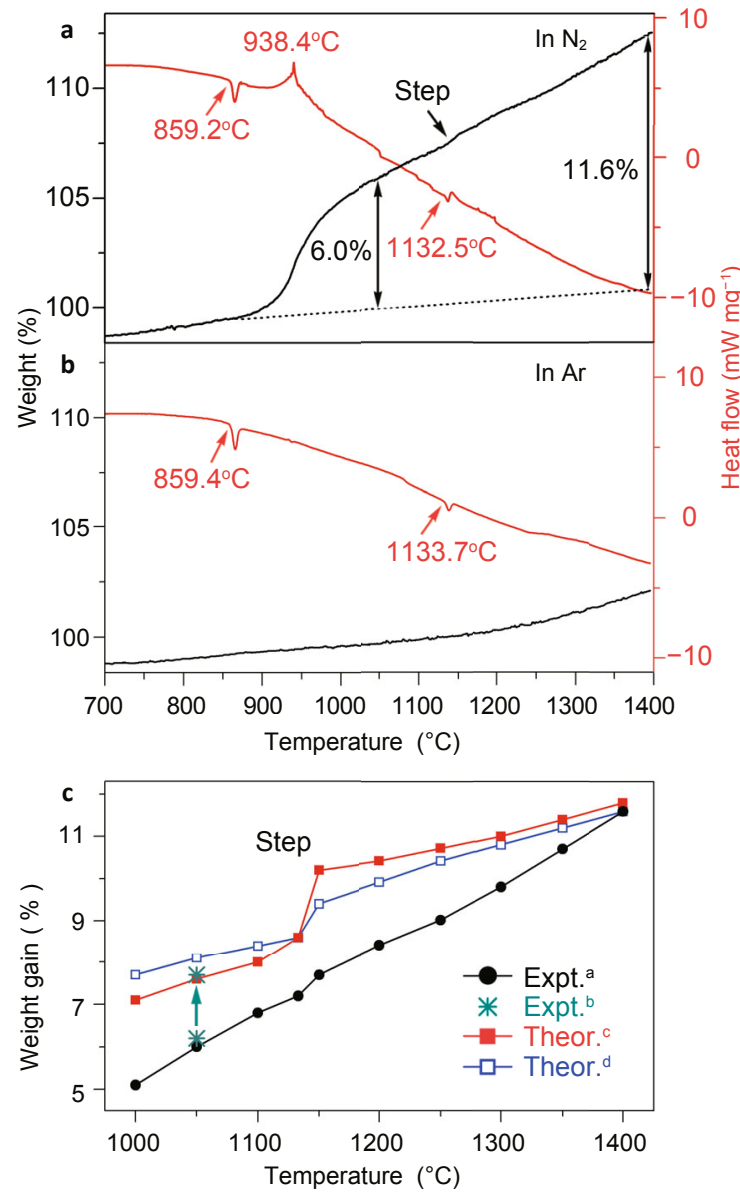

Figure 4 Thermal analysis on the $\mathrm{Al}_{69} \mathrm{Ni}_{31}$ alloy particles in $\mathrm{N}_{2}$ or Ar flow with the heating rate of $10^{\circ} \mathrm{C} \mathrm{min}^{-1}$. (a) TG-DSC curves in $\mathrm{N}_{2}$. (b) TGDSC curves in Ar. (c) Theoretical and experimental weight gains vs. temperature in $\mathrm{N}_{2}$. Expt. ${ }^{\mathrm{a}}(-\bullet-)$ ) a replotting of TG curve in (a). Expt. ${ }^{\mathrm{b}}(*)$ : the weight gains at beginning $(6.2 \%)$ and 40 min later (7.7\%) during the temperature-keeping control experiment at $1050^{\circ} \mathrm{C}$ (Fig. S7a). The arrow indicates the increasing trend with time prolonging. Theor. ${ }^{c}(--)$ and Theor. ${ }^{\mathrm{d}}(-\square-)$ : theoretical calculations with reference to the experimental [18] and calculated [21] phase diagrams, respectively (SI 8).

imize the influence of kinetic limitation as reflected in our TG-DSC control experiment (Figs 4c and S7). In contrast, by controlling or utilizing the kinetic process, it can provide a non-equilibrium alternative to create some unique nanostructures, as demonstrated in the updated progress in the Al-Si catalyzed growth of the Al-doped Si nanowires with $\mathrm{Al}$ content far beyond the equilibrium range [26]. These two complementary approaches are actually becoming the most powerful methods in the design and creation of various nanostructures today.

\section{CONCLUSIONS}

We demonstrated the successful prediction for the growth of AlN nanowires for the first time by nitriding $\mathrm{Al}_{69} \mathrm{Ni}_{31}$ particles across the liquid-solid $(\beta)$ phase region (1133$\left.1638^{\circ} \mathrm{C}\right)$, which based on the PED-VLS mechanism. All the related predictions on the evolutions of the nanowires and coexisting bulk alloys were experimentally confirmed quantitatively. The predictions further corroborate the validity of the PED-VLS mechanism. The applicability of the mechanism has also been specified by two preconditions, i.e., the appearance of liquid-solid two-phase coexistence and the selective reaction of the introduced gaseous reactant with the liquid phase. This progress demonstrates a transformation from the empirical science in nanomaterial synthesis into the prediction and design based on the deep insight into the growth mechanism, which is significant for controllable synthesis, functionalization and applications.

Received 20 November 2015; accepted 28 December 2015; published online 8 January 2016

1 Wang X, Zhuang J, Peng Q, et al. A general strategy for nanocrystal synthesis. Nature, 2005, 437: 121-124

2 Morin SA, Bierman MJ, Tong J, et al. Mechanism and kinetics of spontaneous nanotube growth driven by screw dislocations. Science, 2010, 328: 476-480

3 Meng F, Morin SA, Forticaux A, et al. Screw dislocation driven growth of nanomaterials. Acc Chem Res, 2013, 46: 1616-1626

4 Wagner RS, Ellis WC. Vapor-liquid-solid mechanism of single crystal growth. Appl Phys Lett, 1964, 4: 89-90

5 Morales AM, Lieber CM. A laser ablation method for the synthesis of crystalline semiconductor nanowires. Science, 1998, 279: 208-211

6 Xia YN, Yang PD, Sun YG, et al. One-dimensional nanostructures: synthesis, characterization, and applications. Adv Mater, 2003, 15: 353-389

7 Wacaser BA, Dick KA, Johansson J, et al. Preferential interface nucleation: an expansion of the VLS growth mechanism for nanowires. Adv Mater, 2009, 21: 153-165

8 Tian BZ, Xie P, Kempa TJ, et al. Single-crystalline kinked semiconductor nanowire superstructures. Nat Nanotech, 2009, 4: 824-829

9 Wu YY, Yang PD. Direct observation of vapor-liquid-solid nanowire growth. J Am Chem Soc, 2001, 123: 3165-3166

10 Hannon JB, Kodambaka S, Ross FM, et al. The influence of the surface migration of gold on the growth of silicon nanowires. Nature, 2006, 440: 69-71

11 Kodambaka S, Tersoff J, Reuter MC, et al. Diameter-independent kinetics in the vapor-liquid-solid growth of Si nanowires. Phys Rev Lett, 2006, 96: 096105

12 Glas F, Harmand JC, Patriarche G. Why does wurtzite form in nanowires of III-V zinc blende semiconductors? Phys Rev Lett, 2007, 99: 146101

13 Sutter E, Sutter P. Phase diagram of nanoscale alloy particles used for vapor-liquid-solid growth of semiconductor nanowires. Nano Lett, 2008, 8: 411-414

14 Kim BJ, Tersoff J, Kodambaka S, et al. Kinetics of individual nucleation events observed in nanoscale vapor-liquid-solid growth. Science, 2008, 322: 1070-1073

15 Oh SH, Chisholm MF, Kauffmann Y, et al. Oscillatory mass transport in vapor-liquid-solid growth of sapphire nanowires. Science, 2010, 330: 489-493 
16 Chou YC, Hillerich K, Tersoff J, et al. Atomic-scale variability and control of III-V nanowire growth kinetics. Science, 2014, 343: 281 284

17 He CY, Wang XZ, Wu Q, et al. Phase-equilibrium-dominated vapor-liquid-solid growth mechanism. J Am Chem Soc, 2010, 132: 4843-4847

18 Nash P, Singleton MF, Murray JL. Al-Ni phase diagram, ASM Handbook Volume 3: Alloy Phase Diagrams. Materials Park: ASM International, 1992

19 Zhang XH, Shao RW, Jin L, et al. Helical growth of aluminum nitride: new insights into its growth habit from nanostructures to single crystals. Sci Rep, 2015, 5: 10087

20 Meng F, Estruga M, Forticaux A, et al. Formation of stacking faults and the screw dislocation-driven growth: a case study of aluminum nitride nanowires. ACS Nano, 2013, 7: 11369-11378

21 Al-Ni phase diagram. Data from FSstel-FactSage steel alloy databases $2010 .<$ http://www.crct.polymtl.ca/fact/phase_diagram.php? file=Al-Ni.jpg\&dir $=$ FSstel $>$

22 Bradley AJ, Taylor A. An X-ray analysis of the nickel-aluminium system. Proc R Soc London Ser A, 1937, 159: 56-72

23 Taylor A, Doyle NJ. Further studies on the nickel-aluminum system. I. The b-NiAl and d- $\mathrm{Ni}_{2} \mathrm{Al}_{3}$ Phase Fields. J Appl Cryst, 1972, 5: 201-209

24 Huo KF, Hu YM, Fu JJ, et al. Direct and large-area growth of one-dimensional $\mathrm{ZnO}$ nanostructures from and on a brass substrate. J
Phys Chem C, 2007, 111: 5876-5881

25 Sheng X, Wang L, Chang LT, et al. Growth and photoelectrochemical properties of ordered $\mathrm{CuInS}_{2}$ nanorod arrays. Chem Commun, 2012, 48: 4746-4748

26 Moutanabbir O, Isheim D, Blumtritt H, et al. Colossal injection of catalyst atoms into silicon nanowires. Nature, 2013, 496: 78-82

Acknowledgments This work was supported by the National Natural Science Foundation of China (NSFC) (21073085, 21173115 and 21373108), the Major State Basic Research Development Program of China (2013CB932902) and the Priority Academic Program Development of Jiangsu Higher Education Institutions.

Author contributions $\mathrm{Hu} \mathrm{Z}$ and $\mathrm{Wu} \mathrm{Q}$ conceived and supervised the project; Zhang Y, Wu Q, Wang X and Hu Z designed the experiments; Zhang Y, Cai J, Wu Q and Wang X carried out the experiments; Hu Z, Wu Q, Zhang Y, Cai J, Yang L, He C and Wang X analysed the data and prepared the manuscript. $\mathrm{Hu} \mathrm{Z}$ and $\mathrm{Wu} \mathrm{Q}$ are co-corresponding authors of this manuscript. All the authors participated in discussions of the research.

Conflict of interest The authors declare that they have no conflict of interest.

Supplementary information Supporting data are available in the online version of the paper. 


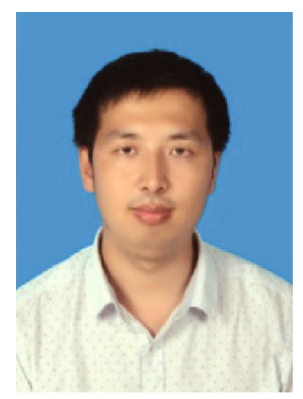

Yongliang Zhang is currently a lecturer at Hefei University of Technology, China. He obtained his BSc degree (2008) in applied chemistry from Nanjing University of Information Science \& Technology, and $\mathrm{PhD}$ degree (2015) in chemistry from Nanjing University. His research interests focus on the design and field emission property of one-dimensional nanostructures.

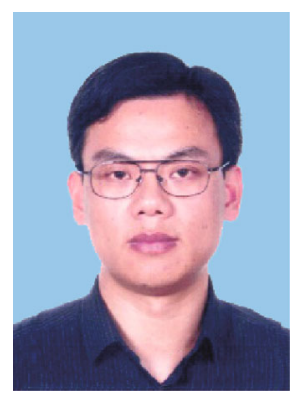

Qiang Wu is currently a professor at the School of Chemistry and Chemical Engineering, Nanjing University, China. He obtained his BSc (1999) and PhD (2004) degrees in chemistry from Nanjing University. His research interests focus on the rational design of nano- and meso-structured materials and their applications in field emission, energy storage, and electrocatalysis.

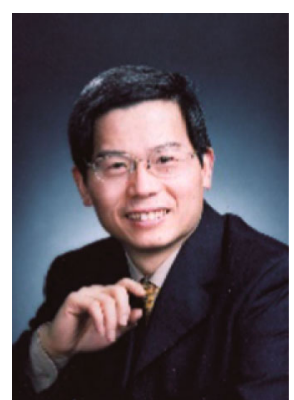

Zheng Hu is currently a Cheung Kong Scholar professor at the School of Chemistry and Chemical Engineering, Nanjing University, China. He received his BSc (1985) and PhD (1991) degrees in physics from Nanjing University. He is the owner of the highly competitive NSFC fund for outstanding young scientists of China (2005). His current research interests focus on physical chemistry and materials chemistry addressing the growth mechanism, materials design and energy applications of a range of nano- and meso-structured materials.

\section{相平衡主导的气-液-固生长机理: 进一步的证据}

张永亮, 蔡婧, 吴强, 王喜章, 杨立军, 何承雨, 胡征

摘要 纳米材料的预测和设计是纳米科学与技术领域的长期梦想, 该梦想的实现有赖于对生长机理的深刻理解. 本文基于我们前期研究揭示 的相平衡主导的气-液-固(VLS)生长机理，成功地预测了在 $1133 \sim 1638^{\circ} \mathrm{C}$ 温区内通过氮化 $\mathrm{Al}_{69} \mathrm{Ni}_{31}$ 合金颗粒生长 $\mathrm{AlN}$ 纳米线的过程, 有关 $\mathrm{AlN}$ 纳米 线的生长、共存Al-Ni合金相的晶格参数及形貌演变等预测均得到了定量化实验结果的证实, 并界定了相平衡主导的VLS生长机理的适用条件. 本文为相平衡主导的VLS生长机理的有效性提供了进一步的实验证据, 同时展示了在生长机理的指导下根据相图设计和制备纳米材料的一个 实例. 